\title{
The Analysis of Slope Stability and Control Project of Slippery Ground Accumulation
}

\author{
LI Yan \\ ChangSha University of Science \& Technology \\ Key Laboratory of Road Structure \& Material, Ministry of Transport of PRC \\ ChangSha, China \\ prettyboy86@163.com
}

\begin{abstract}
Many sliding strata exist in the Three Gorge Reservoir and the weathering products will landslide easily. Aiming at the accumulation formation of Triassic Padang Group in Beipei Landslide treatment project, this paper applied parameters reduction method to analysis the deformation mechanism and stability of the slope. Then the prevention and treatment measures were presented, aslo the reliability of the prevention projects of highway subgrade slope was analyzed. Completion of the Beipei Landslide Treatment Project for one year has proved that analysis and evaluation as well as treatment project are reasonable and effective.
\end{abstract}

Keywords-Sliding strata; Slope Stability; Deformation mechanism; Control project; Slippery Ground Accumulation

\section{INTRODUCTION}

Survey shows that, more than 50\% large geological hazards in Three Gorge Reservoir development of Triassic Padang group 、 Jurassic Zhenzhuchong group and the quaternary collapse accumulation strata. This kind of formation called the slippery ground strata. The accumulation of Beipei slope is the accumulation of Triassic Padang group. The bed rock is the mudstone of Padong group. Because of the influence of rainfall, the slope has distorted since April 2010, and deformation degree increased gradually. The slope has crept due to continuous heavy rainfall. The leading edge of slope was extruded, so there were many penetrating cracks on the leading edge body of slope, also there were many tensile cracks, drunkard forest and scarp at trailing edge of slope, the civil houses have been destroyed. Once the slope failure, it will impact the safety of the pedestrians and cars. So the current situation of slope stability and the development trends of the distortion of the slope must be evaluated, also appropriate treatment measures should be adopt to control the distortion of the Beipei Landslide [1].

Aiming at debris slope, the residual shear strength of slip soil samples was obtained based on laboratory soil test, the shear strength parameters of slip soil was determined combined with parameter inversion, the slope stability was checked by using FLAC, the corresponding treatment scheme were put forward according to the analytic results.

\section{ANALYSIS OF SLOPE DEFORMATION AND INSTABILITY MECHANISM}

A. The slope deformation

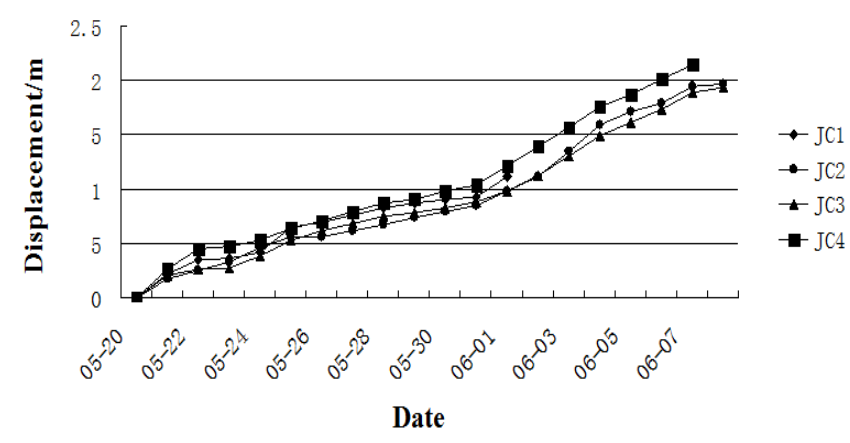

Figure 1. Time-displacement curve

In order to provide evidence for evaluation of slope stability, there were 8 distortion monitoring points in the slope. The observation time was from May 20 to June 7, it was the rainy season during that time, the lateral displacement of each monitoring points are shown in the figure 1. As is shown in the figure, the speed of lateral displacement was faster, and the displacement of leading edge of slope was more than the trailing edge. Retrogressive sliding came into being easily. The displacement of each monitoring points reached to $2 \mathrm{~m}$ by June 7. Thus it can be seen that the slip surface has penetrated, the landslide has occurred because of slope failure.

\section{B. Analysis of instability mechanism}

The slope had the following features:

(1)The slope aspect of the slope was in accord with strata dip, which was bedding slope; The landslide bed was mudstone which was crack closure; the property of the mudstone was soft and tough. There were groundwater and runoff flow at the interface of rock and soil. The weak rock was easy to muddy and soften; the soil mass of the slope was possible to slide along the slip surface.

(2)The rainfall of landslide area was rich, the slide mass was colluvial accumulation rock and soil, it has some hollow parts evidently, the surface water would 
infiltrate to bedrock surface easily, meteoric water would became ground water along the void within slide mass, so it provided the conditions for underlying mudstone to slime and soften.

(3)The landslide bed was mudstone of Padang group, its mechanical strength was lower, and it contained a great deal of hydrophilic minerals, the shallow part of landslide bed was weathered to form weak belt easily.

There was free face in the front margin area because the toe of slope was excavated when the road was building. The density of slide mass will increase in the presence of rainfall and groundwater, part of leading edge of slope has slidden, also the trailing edge slid because it was pulls by the leading edge. Therefore, artificial excavation, rainwater soak into accumulation body and bedrock, sliding strength reduce, leading to the landslide.

\section{PARAMETER INVERSION AND STABILITY ANALYSIS}

\section{A. The geotechnical physical mechanics experiments}

The results of exploration and survey showed that, the slide belt was single, which located in the transition zones between stony soil and Padang group mudstone, the upper regions of slope was gravelly soil with better permeability, the bottom part of slope was mudstone with relative impermeability, The groundwater collected on the top of the water resisting floor, a layer of gray and white clay was formed on the top of the mudstone, and the gray and white clay contained a small amount of montmorillonite, the connectivity of slip surface was better, most of slip soil was silty clay and intense weathering interbedded mudstone, the surface of stone was smooth, the psephicity was high, slip surface was smooth with greasy luster, the threadiness scratches on the slip surface which in the coastean were clear.

1) The in-situ test and result analysis:Two groups of the large bulk density test were carried out, the result as tabled 1. The natural unit weight of sliding mass is 22.4 $\mathrm{KN} / \mathrm{m}^{3}$, saturation unit weigh is $23.1 \mathrm{KN} / \mathrm{m}^{3}$.

TABLE I. RESULT OF LARGE BULK DENSITY TEST

\begin{tabular}{|c|c|c|c|}
\hline $\begin{array}{c}\text { Test } \\
\text { number }\end{array}$ & $\begin{array}{c}\text { Natural } \\
\text { unit } \\
\text { weight } \\
(\mathbf{K N} / \mathbf{m} 3)\end{array}$ & $\begin{array}{c}\text { Saturation } \\
\text { unit } \\
\text { weigh } \\
(\mathbf{K N} / \mathbf{m} 3)\end{array}$ & Description of soil \\
\hline$\gamma 1$ & 22.50 & 23.30 & Block and detritus \\
\hline$\gamma 2$ & 22.30 & 22.90 & Block and detritus \\
\hline
\end{tabular}

2) Laboratory test and result analysis:Soil samples were original slip soil, the soil was taken in the drill by using the thin wall sampler or excavated in the coastean, the coarse particle was got rid of when doing experiment. The soil samples were sealed with plastic bag sand placed appropriately, and submitted in time.

TABLE II. PHYSICAL PROPERTIES OF SLIP SOIL

\begin{tabular}{|c|c|c|c|c|c|c|c|c|c|c|}
\hline & $\begin{array}{c}\text { Water } \\
\text { content } \\
(\%)\end{array}$ & $\begin{array}{c}\text { Saturation } \\
(\%)\end{array}$ & $\begin{array}{c}\text { Plasticity } \\
\text { index } \\
(\%)\end{array}$ & $\begin{array}{c}\text { Liquid } \\
\text { Limit } \\
(\%)\end{array}$ & $\begin{array}{c}\text { Free } \\
\text { swelling } \\
\text { ratio } \\
(\%)\end{array}$ & $\begin{array}{c}\text { Liquid } \\
\text { Limit } \\
\text { (\%) }\end{array}$ & $\begin{array}{c}\text { Natural } \\
\text { Unit } \\
\text { Weight } \\
\text { (KN/ m3) }\end{array}$ & $\begin{array}{c}\text { Saturate } \\
\text { d Unit } \\
\text { Weight } \\
\text { (KN/m3) }\end{array}$ & $\begin{array}{c}\text { Free } \\
\text { swelling } \\
\text { ratio } \\
(\%)\end{array}$ & $\begin{array}{c}\text { Liquid } \\
\text { Limit } \\
(\%)\end{array}$ \\
\hline Minimum & 25.60 & 89.81 & 13.6 & 32.7 & 8 & 19.1 & 19.0 & 19.7 & 8 & 19.1 \\
\hline Minimum & 29.00 & 95.6 & 16.7 & 37.7 & 47 & 21 & 19.8 & 20.3 & 47 & 21 \\
\hline Average & 27.17 & 92.53 & 15.53 & 35.74 & 21.67 & 20.21 & 19.3 & 20.0 & 21.67 & 20.21 \\
\hline
\end{tabular}

TABLE III. MECHANICAL PROPERTIES OF SLIP SOIL

\begin{tabular}{|c|c|c|c|c|c|c|c|c|}
\hline & \multicolumn{2}{|c|}{$\begin{array}{c}\text { Shear strength of } \\
\text { natural }\end{array}$} & \multicolumn{2}{|c|}{ Saturated shear strength } & \multicolumn{2}{|c|}{$\begin{array}{c}\text { Residual shear } \\
\text { strength of natural }\end{array}$} & \multicolumn{2}{|c|}{$\begin{array}{c}\text { Saturated residual shear } \\
\text { strength }\end{array}$} \\
\hline & $\begin{array}{l}\text { Cohesion } \\
\text { (KPa) }\end{array}$ & $\begin{array}{l}\text { Friction } \\
\left.\text { Angle ( }{ }^{\circ}\right)\end{array}$ & $\begin{array}{l}\text { Cohesion } \\
\text { (KPa) }\end{array}$ & $\begin{array}{l}\text { Friction } \\
\left.\text { Angle ( }{ }^{\circ}\right)\end{array}$ & $\begin{array}{c}\text { Cohesion } \\
\quad(\mathrm{KPa})\end{array}$ & $\begin{array}{c}\text { Friction } \\
\left.\text { Angle ( }{ }^{\circ}\right)\end{array}$ & $\begin{array}{l}\text { Cohesion } \\
\text { (KPa) }\end{array}$ & $\begin{array}{l}\text { Friction } \\
\text { Angle }\left({ }^{\circ}\right)\end{array}$ \\
\hline Minimum & 23 & 12.17 & 15 & 9.17 & 11 & 9.13 & 8 & 6.37 \\
\hline Maximum & 31 & 14.6 & 19 & 11.3 & 16 & 11.42 & 12 & 8.17 \\
\hline Average & 27.0 & 13.35 & 17.29 & 10.23 & 13.43 & 10.31 & 10.14 & 7.2 \\
\hline
\end{tabular}

TABLE IV. MECHANICAL PROPERTIES OF SLIP SOIL

\begin{tabular}{|c|c|c|c|c|c|c|}
\hline \multirow{2}{*}{$\begin{array}{c}\text { Natural Unit } \\
\text { Weight } \\
\text { (kN/m3) }\end{array}$} & \multirow{2}{*}{$\begin{array}{l}\text { softening } \\
\text { coefficient }\end{array}$} & \multirow{2}{*}{$\begin{array}{c}\text { Natural Uniaxial } \\
\text { Compressive } \\
\text { Strength } \\
\text { Standard Value } \\
\text { (MPa) }\end{array}$} & \multirow{2}{*}{$\begin{array}{l}\text { Saturated Uniaxial } \\
\text { Compressive } \\
\text { Strength Standard } \\
\text { Value (MPa) }\end{array}$} & \multirow{2}{*}{$\begin{array}{c}\text { Average of } \\
\text { Tensile } \\
\text { Strength (MPa) }\end{array}$} & \multicolumn{2}{|c|}{$\begin{array}{l}\text { Average of trail shear } \\
\text { strength }\end{array}$} \\
\hline & & & & & $\begin{array}{l}\text { Cohesion } \\
\text { (MPa) }\end{array}$ & $\begin{array}{l}\text { Friction } \\
\text { Angle }\left(^{\circ}\right)\end{array}$ \\
\hline 25.04 & 0.63 & 4.3 & 2.6 & 0.28 & $0.91 \sim 1.46$ & 35 \\
\hline
\end{tabular}


TABLE V. RESULT OF INVERSION ANALYSIS OF MECHANICAL PARAMETERS OF SLIP SOIL

\begin{tabular}{|c|c|c|c|c|c|c|c|c|}
\hline \multirow{2}{*}{\multicolumn{2}{|c|}{$\mathbf{K}_{f}$}} & \multicolumn{7}{|c|}{$c$} \\
\hline & & 7 & 8 & 9 & 10 & 11 & 12 & 13 \\
\hline \multirow{5}{*}{$\varphi$} & $\varphi=8$ & 0.78 & 0.800 & 0.820 & 0.840 & 0.860 & 0.890 & 0.910 \\
\hline & $\varphi=9$ & 0.86 & 0.880 & 0.900 & 0.920 & 0.950 & 0.970 & 0.990 \\
\hline & $\varphi=10$ & 0.94 & 0.960 & 0.990 & 1.010 & 1.030 & 1.050 & 1.070 \\
\hline & $\varphi=11$ & 1.03 & 1.050 & 1.070 & 1.090 & 1.110 & 1.130 & 1.150 \\
\hline & $\varphi=12$ & 1.11 & 1.130 & 1.150 & 1.170 & 1.200 & 1.220 & 1.240 \\
\hline
\end{tabular}

The result of test showed that (Tabled 2, Tabled 3), the natural water content of slip soil was larger than the plastic limit generally, the results showed that the shale mudding degree of slip soil was higher; The inner friction angle of residual strength which acquired from the first experiment was very close to the one which acquired from repeat shear experiment. It is seen that the mechanical properties of the slip soil were influenced by the structural perturbations slightly, while influenced by the saturated water considerably.

The rock sample of mudstone of Padang group was taken by drill sampling, the experimental result of the physical mechanics experiment of slide bed was showed in Tabled 4.

The coarse particle was got rid of when did the physical mechanics properties experiment of slip soil, so the parameters acquired from experiment cannot reflect the mechanical properties of original slip soil[2]. The shear strength parameter of slip soil was determined according to the residual shear strength based on laboratory soil test combined with parameter inversion to provide the evidence for stability calculation of landslide control design.

\section{B. Inversion analysis of mechanical parameters of slip soil}

Bishop method based on limit equilibrium theory applied to inverse mechanical parameters of slip soil[2,3]. I - I' section of the slope was analyzed as the objects, which the situations were gravity loads and rainstorm, the results are shown in Table 5.

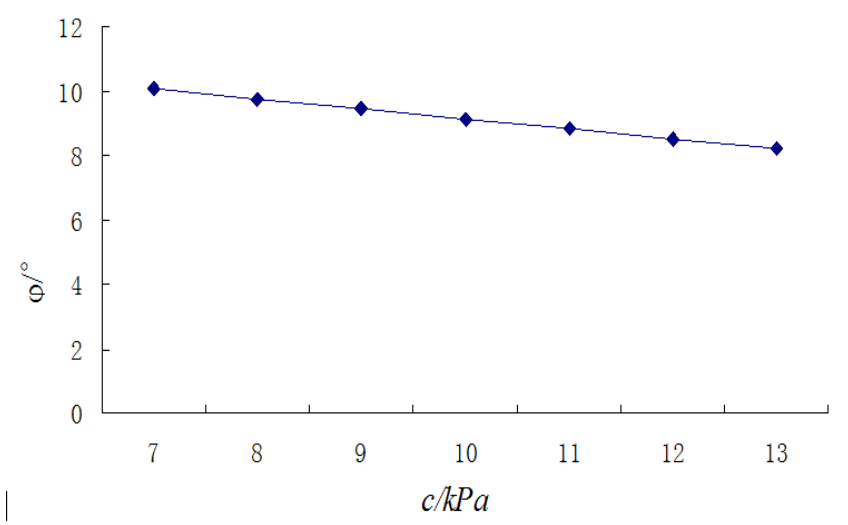

Figure 2. $\quad\left(\mathrm{K}_{f}=0.98\right) c-\varphi$ curve
2.

The relationship between $\mathrm{K}_{f}, c, \varphi$ is shown in figure

The figure 2 showed that every $1 \mathrm{kpa}$ increase of the $c$, the $\mathrm{K}_{f}$ increased 0.02 ; Every $1 \mathrm{kpa}$ increase of the $\varphi$, the $\mathrm{K}_{f}$ increased 0.08 . So the $\varphi$ was more sensitive than the $c$ for the stability of slope.

The slope body has deformed and there has been through cracks and more water seepage points at the border of the slope because of rainfall. According to the monitoring station known that the slope was creeping and the displacement was larger. The safety parameters was selected from 0.95 to 1.0 based on 《Code for investigation of geotechnical engineering 》(GB500212001); I - I' section of the slope was adopted as research models, the condition was dead weight and rainstorm, the stability coefficient of the slope was 0.98 . The laboratory soil test results showed that the average of residual shear strength of natural of the slip soil was $13.43 \mathrm{KPa}$, the average of saturated residual shear strength of the slip soil was $10.14 \mathrm{KPa}$; Because there was crushed mudstone in the slip soil, so the value of the $\mathrm{c}$ reduced to $10.0 \mathrm{KPa}$.

The table of the relation of $c-\varphi$ as shown in table 5 when the $\mathrm{K}_{f}=0.98$.

The relationship between $c, \varphi$ is shown in figure 3 .

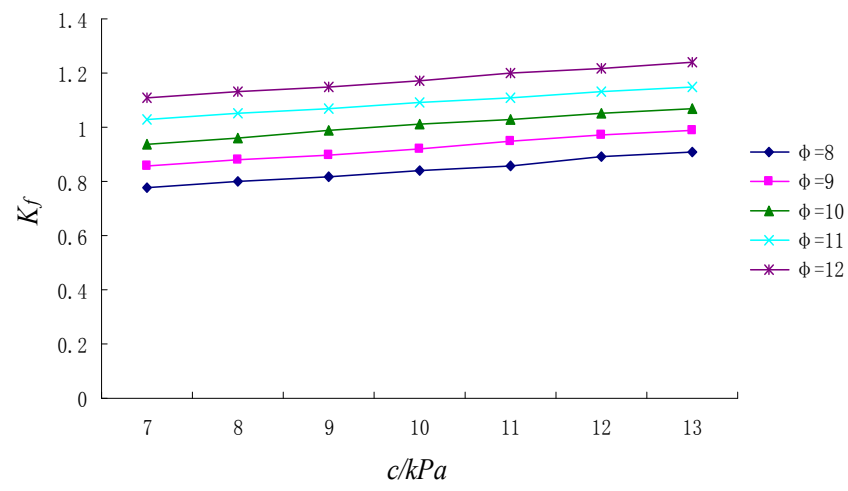

Figure 3. Shear strength parameters curve 
TABLE VI. THE FIGURE OF THE RELATION OF C- $\Phi$

\begin{tabular}{|c|c|c|c|c|c|c|c|}
\hline$c(\mathrm{KPa})$ & 7 & 8 & 9 & 10 & 11 & 12 & 13 \\
\hline$\varphi\left({ }^{\circ}\right)$ & 10.09 & 9.76 & 9.46 & 9.15 & 8.83 & 8.51 & 8.20 \\
\hline
\end{tabular}

The friction angle $\varphi=9.1^{\circ}$ was acquired by the $c-\varphi$ curve. The parameters of shear strength of natural of the slip soil $c=13 \mathrm{KPa}, \varphi=12^{\circ}$ was determined according to the result of experiment also combined with the empirical value of Three Gorge Reservoir; The saturated shear strength $c=10 \mathrm{KPa}, \varphi=9.1^{\circ}$.

\section{Stability Analysis}

Fast Lagrangian Analysis of Continue based on strength reduction method has been widely applied on slope engineering recently[4-8]. In this paper, the stability of the slope was analyzed by FLAC which based on strength reduction method. According to geological section known that the horizontal distance of the I - I ' section was $240 \mathrm{~m}$, vertical distance was $92 \mathrm{~m}$. The sliding mass and sliding zone as concerned object, so one grid represents $1 \mathrm{~m}$ in this region, the thickness of sliding zone was $0.6 \mathrm{~m}$. In order to reduce computational time, larger grids were applied in the region of bedrock; The grids were extended which the gradual change ratio was 0.5 . The boundary conditions were both sides of the model $[9,10]$. The grid model as shown in figure 4 .

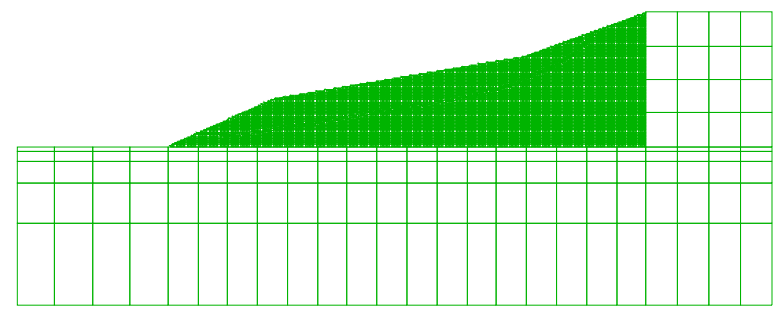

Figure 4.The FLAC grid model

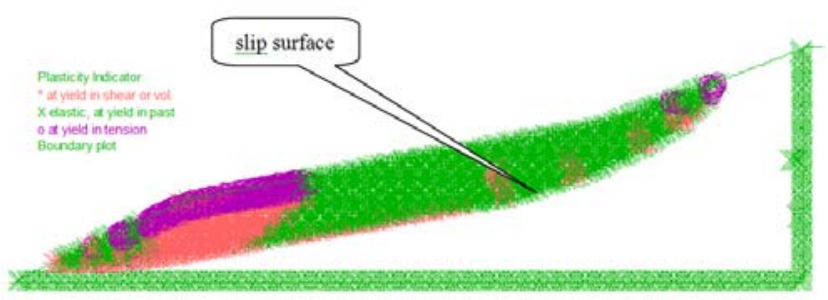

Figure 5. The plastic zone of slope

The safety factor was 0.99 by numerical calculation, there were plastic zones which nearly through in the leading edge body of slope from Figure 5. The slope will failure behind the toe of slope which the distance was $54 \mathrm{~m}$, will failure under the conditions of tension destruction will happen at the upper layer of the slope, the shear destruction will happen at the lower layer of the slope. According to the monitoring station known that there have been many tensile cracks. The results of simulation and inversion were in accord with practical monitoring.

\section{THE TREATMENT MEASURES OF SLOPE}

\section{A. The Choice of treatment scheme}

The characteristic of the landslip was complex; The slope would slide on a large scale even develop towards trailing edges of the slope if the soil of the leading edge body of slope was removed. So the support treatment schemes were adopted as the main treatment. The scheme is the following: Embedded anti-slide pile combined with drainage.

\section{B. Implement proposal of the scheme}

(1)The cracks in the slope should be filled to avoid the anti-sliding force decreasing as the rainfall infiltrated to the slip surface.

(2)The water which flowed from the outlet of the slope should be discharged far from the slope.

(3)Deformation monitoring of the slope should strengthen to ensure the safety in construction.

(4)It is unsuitable to excavate and clear the soil in the front of landslide before the slope was controlled effectively to avoid decreasing the stability of slope.

\section{CONCLUSIONS}

(1) The scale of landslides in three gorges reservoir area was large generally, the potential risk was serious. The parameters of slip soil which acquired from laboratory experiment only reflected the some physical properties of slip surface, it could not reflect the physical properties of the whole slip surface. So the shear strength parameter of the slip soil was synthetically determined combined with parameter inversion, it has great theoretical significance and practical value to study on landslide formation and deformation mechanism and provide evidence for prevention engineering design.

(2) Artificial excavation and rainfall were the major factors to trigger landslide. The rainfall would infiltrate along the void in the landslide and then become ground water under the rainstorm environment, and the underlying mudstone would slime and soften under the action of underground water. There was free face in front of leading edge of slope, the deadweight of slip body and sliding force increased, and the shear strength decreased because the sliding zone was lubricated and softened due to the ground water. Landslide would happen when the sliding force was more than anti-sliding force.

(3) The failure mode obtained by using FLAC of landslide was in accord with the monitoring result.

(4) One year after the completion of the project, the slope was in a stable state according to the monitoring data and the exploration. Therefore, the control scheme was reasonable and effective. 


\section{ACKNOWLEDGEMENTS}

This work was financially supported by Hunan Provincial Innovation Foundation for Postgraduate (CX2014B371).

\section{REFERENCES}

[1] Li Haiping. Emergency Treatment Engineering of Yunhe country, ChengJiang town, Beibei district Engineering Geology Investigation Report[R]. Chongqing Communications Research \& Design Institute, 2010.

[2] Liu Yuguo. Study on Mechanism and Stability of Yangjiaba Landslide in Yunyang county of Three Gorges Reservoir [D] . Chengdu: Chengdu University of technology, 2007.

[3] Liubo,HanYanhui. Principle of FLAC 、 living example and application guides[M].Beijing: China Communications Press,2005.

[4] Wang Xi-bao,Li Tian-bin,XuYong. Two-dimensional Model Simplify Modeling Method and Application[J] The Chinese Journal of Geological Hazard and Control.2006.3(17):5-9
[5] Itasca Consulting Group, Inc. FLAC(Fast Lagrangian Analysis of Continua) Version5.0 [M].U.S.2005.

[6] Wu Hai-ping,Zhang Yuan-kai. Application of FLAC Simulation in Premature Stability Analysis and Evaluation of Post Protection for Land Slide. [J].Technology of Hingway and Transport. 2006(6):1417.

[7] Zhang Shang-yi,Zheng Ying-ren,Shi Wein-min. Analysis on safety factor of slope by strength reduction FEM[J]. Chinese Journal of Geotechnical Engineering, 2002， 24(3):343- 346

[8] Luan Mao-tian,Wu Ya-jun,Nian Ting-kai. An Alternative Criterion for Evaluating Slope Stability Based on Development of Plastic Zone by Shear Strength Reduction FEM [J]. Journal of Disaster Prevention and Mitigation Engineering.2003, 23(3):1- 8.

[9] Chen Zu-yu.The Analysis of Stability of Soil Slope--The principle , method procedure[M]. BeiJing: China WaterPower Press.2005

[10] LI Yuanyao et al. Study on statistical rule of shear strength parameters of soil in landslide zone in Three Gorges Reservoir area [J]. Rock and Soil Mechanics .Vol.29.1419-1424 